Supporting material to accompany

\title{
Highly Porous Fibers by Electrospinning into a Cryogenic Liquid
}

\author{
Jesse T. McCann, ${ }^{\dagger}$ Manuel Marquez, ${ }^{\S}$ and Younan $\mathrm{Xia}^{\dagger *}$ \\ 'Department of Chemistry, University of Washington, Seattle, Washington 98195-1700 \\ §I'NEST Group, New Technology Research Department, PMUSA, Richmond, Virginia 29238
}




\section{Experimental Procedure}

In a typical experiment, poly(styrene) (Aldrich, $\left.\mathrm{M}_{\mathrm{w}}=250,000\right)$ was dissolved in a 2 $\mathrm{mM}$ solution of tetraoctylammonium bromide (Sigma) in N,N'-dimethylacetamide (Aldrich) to make a $20 \% \mathrm{w} / \mathrm{v}$ polymer solution. The solution was driven from the syringe at a constant rate of $0.3 \mathrm{~mL} / \mathrm{h}$ by a KD-20 syringe pump (Stoetling, Carbondale, IL). The fibers were electrospun at $9 \mathrm{kV}$ with a $10 \mathrm{~cm}$ collection distance using a high voltage DC power supply (ES30P-5W, Gamma High Voltage Research, Ormond Beach, FL). The collector was immersed in a bath of liquid nitrogen, which was $\sim 2 \mathrm{~cm}$ in depth and replenished every $5 \mathrm{~min}$. Humidity was controlled to avoid frost formation by replenishing the chamber with air dried over calcium carbonate dessicant. The collected fibers were kept under liquid nitrogen until they were dried in vacuo for $2 \mathrm{~h}$.

Poly(acrylonitrile) (Polysciences, $\left.\mathrm{M}_{\mathrm{w}}=150,000\right)$ was electrospun from a $7 \% \mathrm{w} / \mathrm{v}$ solution in N,N'-dimethylformamide (DMF, Aldrich). Poly(vinylidene fluoride) (Aldrich, $\mathrm{M}_{\mathrm{w}}=275,000$ ) was electrospun from a $20 \% \mathrm{w} / \mathrm{v}$ solution in $2 \mathrm{mM}$ tetraoctylammonium bromide and N,N'-dimethylacetamide. Poly(E-caprolactone) (Scientific Polymer Products, Ontario, NY) was electrospun from a $15 \% \mathrm{w} / \mathrm{v}$ solution in chloroform (Fisher).

The fibers were broken for imaging by freeze-fractionation with liquid nitrogen, followed by drying in a dessicator. SEM images were obtained by sputtering with $\mathrm{Au} / \mathrm{Pd}$ alloy for $30 \mathrm{~s}$. The substrates were tilted by $10^{\circ}$ in order to clearly image the ends of the broken fibers. 


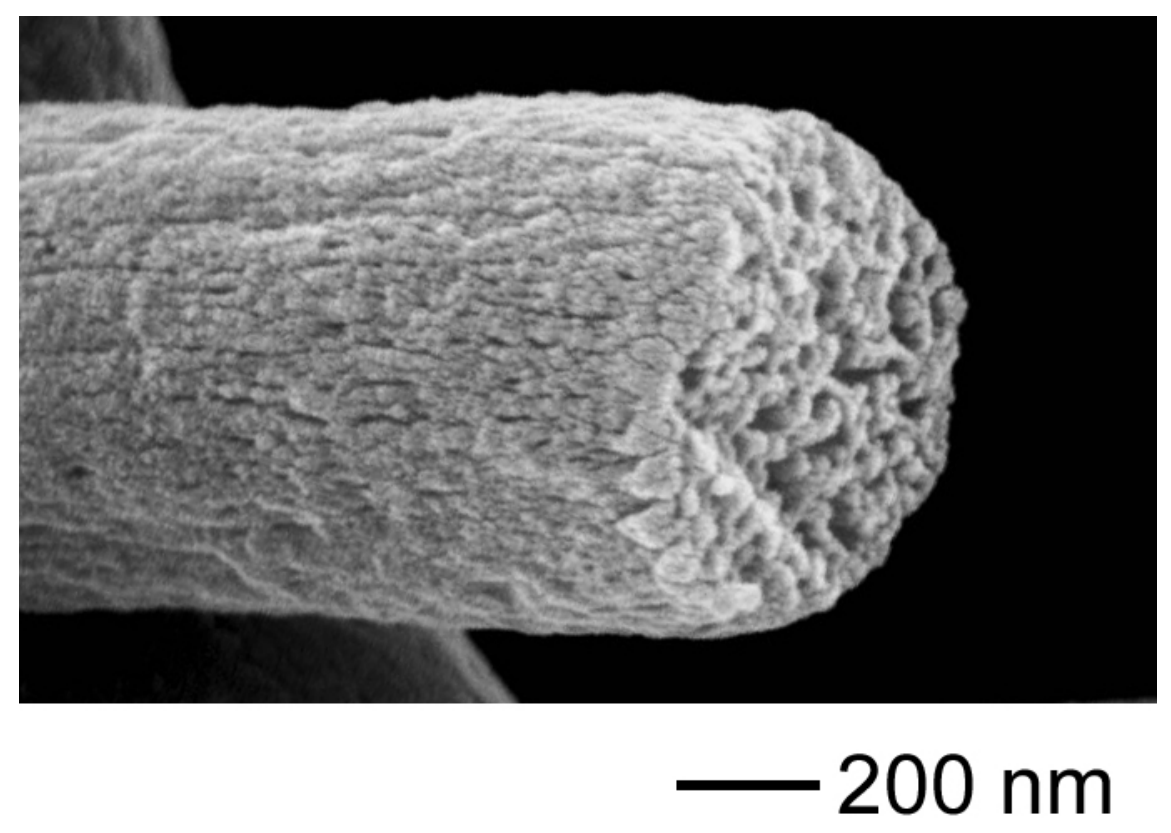

Figure S1. The end of a poly(styrene) nanofiber electrospun into liquid nitrogen and dried in vacuo.

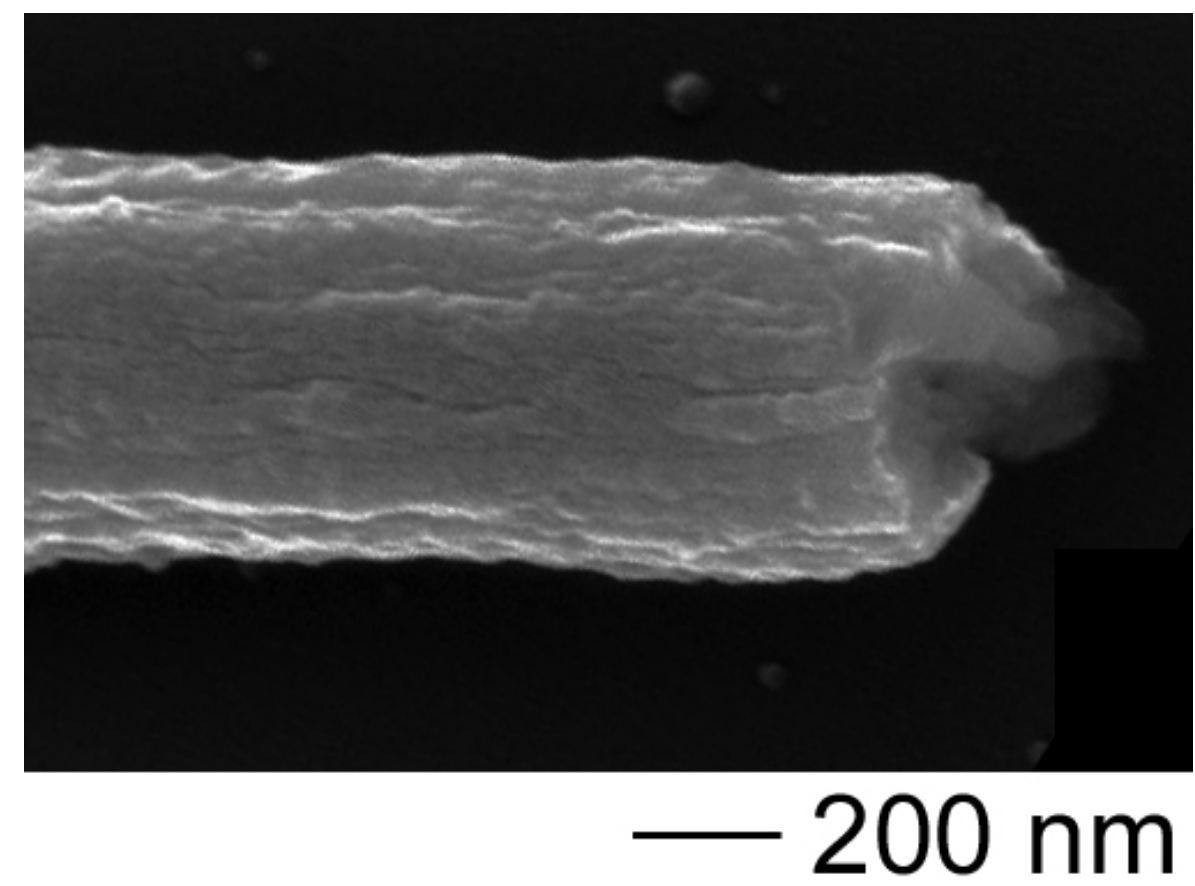

Figure S2. The end of a poly(styrene) fiber electrospun into liquid nitrogen and allowed to reheat rapidly in air. 




Figure S3. SEM of the end of a poly(acrylonitrile) fiber electrospun into liquid nitrogen and dried in vacuo.



Figure S4. (A) SEM of the end of a carbon fiber generated by carbonizing the poly(acrylonitrile) fiber shown in Figure S3. (B) TEM of the carbon fiber. 

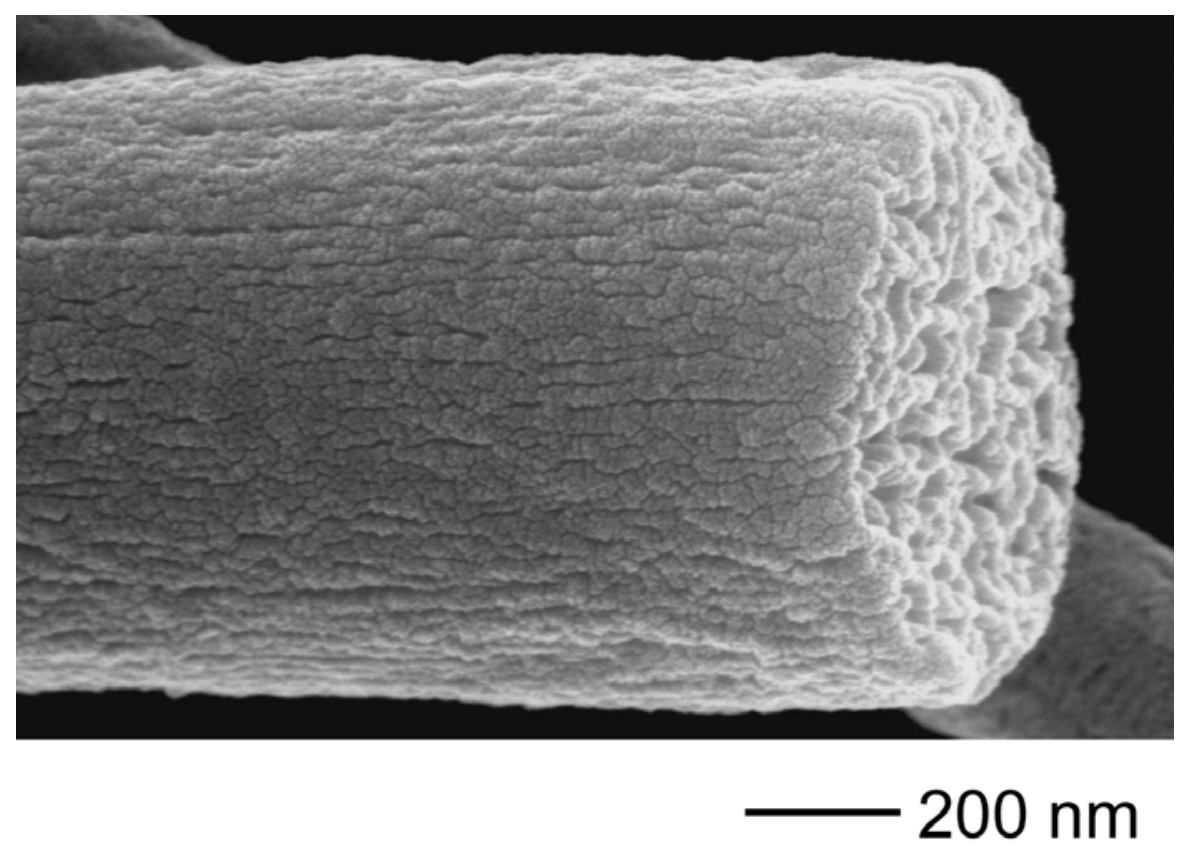

Figure S5. Broken end of a poly(vinylidene fluoride) fiber electrospun into liquid nitrogen and dried in vacuo.

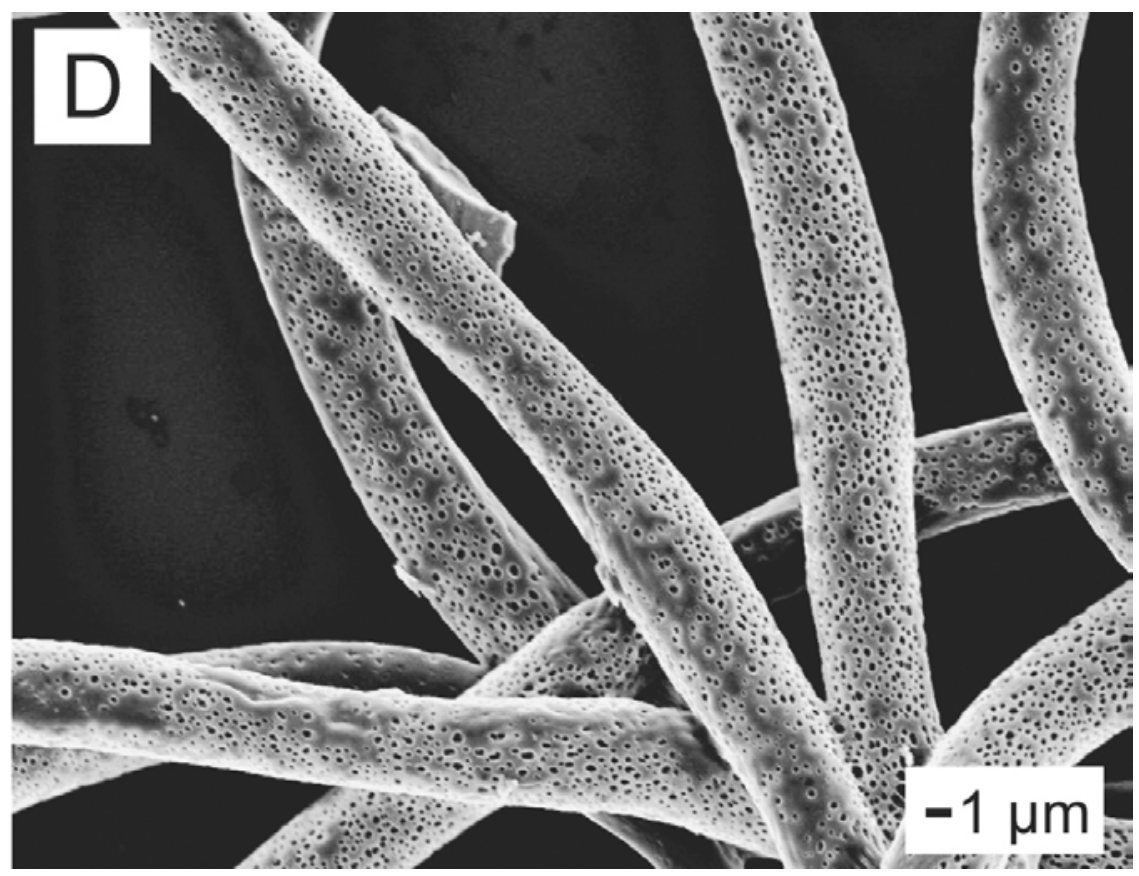

Figure S6. An enlarged version of Figure 2d. 


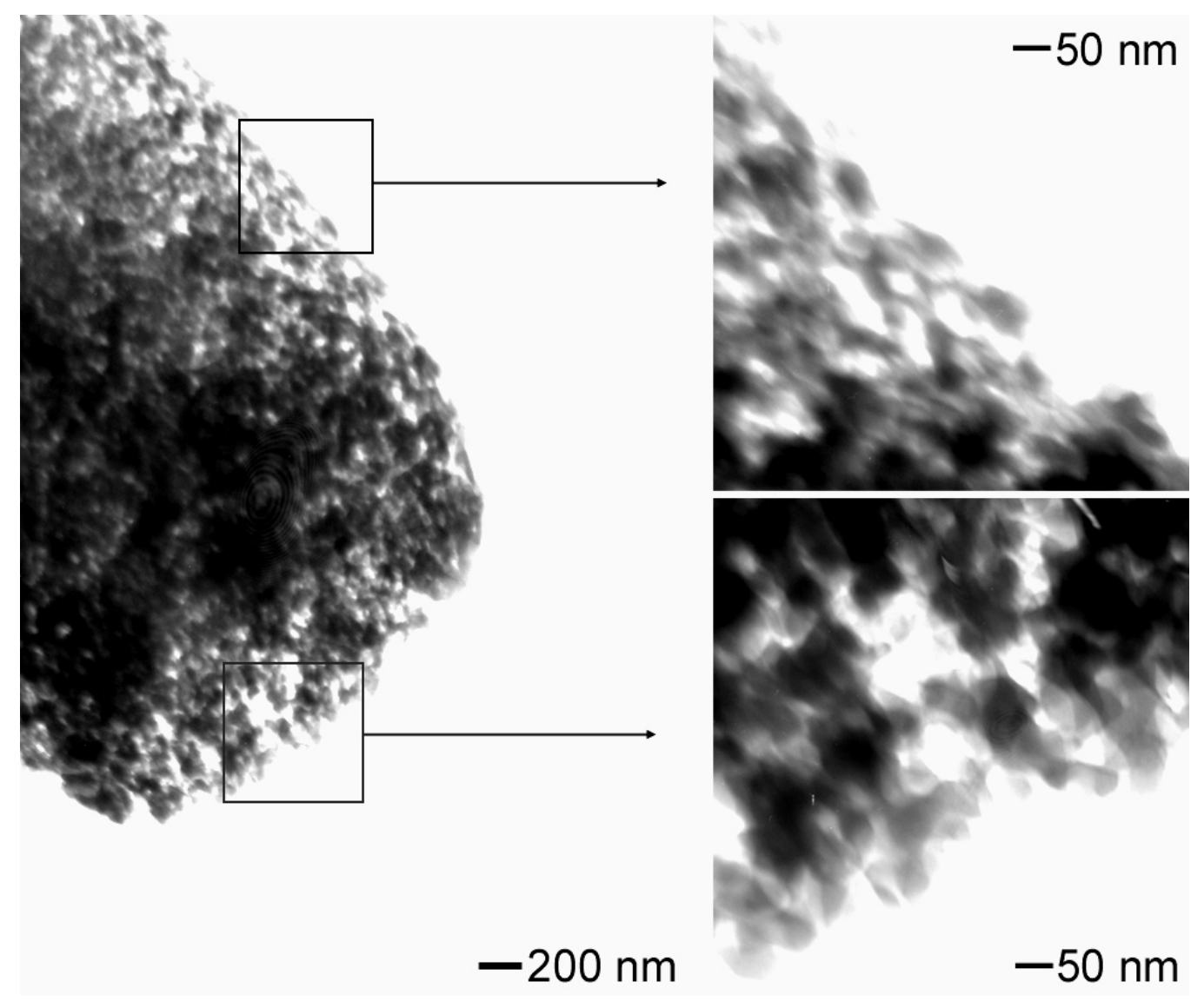

Figure S7. TEM of the end of a poly(styrene) fiber electrospun into liquid nitrogen and dried in vacuo. Insets are at higher magnifications. 